\title{
Ageing effect on swell, shrinkage and flexural strength of sand and waste marble powder stabilized expansive soil
}

\author{
Serife Oncu ${ }^{1}$, Huriye Bilsel ${ }^{2}$ \\ ${ }^{1}$ Eastern Mediterranean University, Famagusta, N. Cyprus \\ ${ }^{2}$ Cyprus International University, Nicosia, N. Cyprus
}

\begin{abstract}
Expansive soils in semi-arid climates must be mitigated to minimize potential structural damage to the overlying structures due to swell-shrink behavior caused by climatic changes. The expansive soil in this study was amended by sand which reduced the swell-shrink potential significantly. As a secondary additive, a waste by product of construction industry was selected, marble powder. Recycling this material would minimize its accumulation and covering a large space in landfill areas. In this study, waste material was assessed as a possible partial replacement for sand and due to its high calcite content, curing effect on its cementitious characteristic was also evaluated. It was observed that for mitigating the swell-shrink potential, 10\% marble powder by dry mass was the optimum amount which was observed to gain improved characteristics with curing. The flexural strength, however, slightly reduced with marble powder addition, the soil mixture displayed a brittle behavior. Therefore the utilization of this material is recommended to be restricted to soils exposed to lower flexural loads, such as light traffic. The correlation between shrinkage strains and flexural strength parameters suggested herein, could be a potential empirical approach to predict the flexural strength based on shrinkage behavior.
\end{abstract}

\section{Introduction}

The swell and shrinkage properties of expansive soils due to climatic effects cause serious damages to the light structures. Many researchers studied the factors which influence the swell-shrink behavior of compacted expansive soils. The influence of compaction dry density and moisture content on the swelling of desiccated clay was investigated by Rao et al. (2000) [1] and concluded that it is actually the initial void ratio which affects the swell potential of the desiccated soils, and not the compaction water content. Conversely, initial moisture content is an important factor for both swelling and shrinkage. According to Chen and Ma (1987) [2] initial dry density is a controlling factor on swelling but not on shrinkage. Day (1994) [3] studied the effect of cyclic wetting-drying on volume change of the compacted silty clay and observed that the swell potential increased which was attributed to the change in clay structure from dispersed to flocculated state with the repeated wettingdrying cycles. Detrimental effects of swelling-shrinking soils on structures are well documented in the literature [4]. To alleviate these effects, various materials such as lime, Portland cement and bitumen are used in the stabilization of swelling soils of which most commonly used are lime and cement [5].

Recently utilization of industrial waste materials such as fly ash, blast furnace slag, cement kiln dust, limestone dust and marble dust as additives became very popular for both recycling and soil improvement purposes. Accumulation of these wastes presents considerable environmental and economical problems, therefore their utilization as stabilizing agent impedes their hazardous effects on the environment and reduces construction costs as well as accumulation of the waste in areas where landfill capacities are restricted. Gandhi (2013) [6] compared marble dust and rice husk ash in the stabilization of expansive soils and showed that marble dust was more effective than rice husk ash. Agrawal and Gupta (2011) [7] studied with varying proportions of marble dust $(0,5,10,15,20,25$ and $30 \%)$ for the expansive soil treatment. They investigated the effect of marble dust on the physical properties of the stabilized soil and reported that liquid limit, plasticity index and shrinkage index decreased after using marble dust. On the other hand, plastic limit and shrinkage limit increased. Abdulla and Majeed (2014) [8] added marble powder with different percentages $(10,20,30 \%)$ by weight of soil. Liquid limit, plastic limit and plasticity index values reduced with the marble dust inclusion. Effect of marble dust addition on compaction characteristics were evaluated by [9, 10]. Çimen et al. (2011) [9] stated that marble content affect the maximum dry density but optimum water content did not change. Sabat and Nanda (2011) [10] stated that maximum dry density showed a decreasing trend and optimum moisture content showed vice versa with the addition of marble dust. Many investigations showed that swelling of soils reduced with

\footnotetext{
$\overline{{ }^{a} \text { Corresponding author: serife.oncu } @ e m u . e d u . t r}$
} 
the utilization of marble dust [7-12]. Cömert et al. (2010) [13] investigated of using fly ash, marble dust and waste sand as additives for two types of soils. They prepared specimens in different percentages and found that $40 \%$ waste materials can be used as a road sub-base. On the other hand, according to unconfined compression test results optimum ratios were found $20 \%$ for fly ash, 5$10 \%$ for marble dust and 5\% for waste sand. Firat et al. (2012) [14] recommended fly ash, marble dust and waste sand are effective stabilizers in road subbases. They indicate that these additives improved swelling ratio, CBR and water conductivity. Gupta and Sarma (2014) [15] used sand, fly ash and marble dust with different proportions in order to improvement of black cotton soil. They concluded that this mixture can be used as a subgrade material for construction of flexible pavements in rural roads with low traffic volume.

This study is focused on the effect of curing time on shrinkage and flexural strength of compacted silt-sand with marble powder additive as a replacement for sand. Flexural strength is an indirect tensile test yielding a measure of toughness and ductility of materials, which are required characteristics of compacted soils mainly as road base. This study also shows a relationship between shrinkage properties and flexural strength.

\section{Materials and methods}

Expansive soil used in this study is classified as silt with high plasticity $(\mathrm{MH})$ according to the Unified Soil Classification System (ASTM D2487), consisting of $42 \%$ clay, $48 \%$ silt and $10 \%$ sand. Sand used in stabilization of expansive soil is poorly graded sand (SP) taken from the eastern coast of Cyprus, with effective diameter $D_{10}$, mean diameter $\mathrm{D}_{50}$, coefficient of uniformity $\mathrm{C}_{\mathrm{u}}$ and coefficient of curvature $C_{c}$ values of $0.16,0.19,1.25$ and 1.013 respectively. Waste marble powder (MP) utilized as a secondary additive, was collected from a marble plant which was freshly accumulated after a cutting process. It is constituted of $6 \%$ clay size, $32 \%$ silt size and $62 \%$ sand size particles. The chemical composition of the expansive silt and waste marble powder obtained using X-ray flourescence spectrometer (XRF) are depicted in Table 1.

Table 1. Chemical composition of natural silt and waste marble powder.

\begin{tabular}{|l|c|c|}
\hline Element & $\begin{array}{c}\text { Expansive } \\
\text { soil }\end{array}$ & $\begin{array}{c}\text { Waste marble } \\
\text { powder }\end{array}$ \\
\hline $\mathrm{SiO}_{2}(\%)$ & 36.5 & 0.178 \\
\hline $\mathrm{CO}_{2}(\%)$ & 17.9 & 42.6 \\
\hline $\mathrm{CaO}(\%)$ & 16.2 & 55.7 \\
\hline $\mathrm{Al}_{2} \mathrm{O}_{3}(\%)$ & 11.8 & 0.0708 \\
\hline $\mathrm{Fe}_{2} \mathrm{O}_{3}(\%)$ & 6.87 & 0.0641 \\
\hline $\mathrm{MgO}(\%)$ & 6.26 & 1.22 \\
\hline Other elements & 4.47 & 0.1671 \\
\hline
\end{tabular}

One-dimensional swell test (ASTM D4546-08) was applied to the compacted soil samples which were at 75 $\mathrm{mm}$ diameter and $15 \mathrm{~mm}$ height. Upon completion of swelling, the specimens were drained and stored in a temperature controlled room for volumetric shrinkage test. Diameter and height of the soil samples were measured at different time intervals on shrinkage path using a digital Vernier caliper, until volume change ceased.

For flexural strength test (ASTM C348-14), soil specimens (beams) were prepared using a special mold which was $40 \mathrm{~mm}$ width, $40 \mathrm{~mm}$ depth and $160 \mathrm{~mm}$ height. These beams were compacted by using static compaction according to maximum dry density and optimum water content values. All samples which were used in swell, consolidation, shrinkage and flexural test were cured for 0,7 and 28-days. Soil specimens were packed and stored in a desiccator.

\section{Experimental Results}

\subsection{Physical properties}

Soil specimens were categorized in five different groups. Group 1 is expansive silt which is denoted by N. Group 2 is $50 \%$ silt and $50 \%$ sand (NS), Group 3 is $47.5 \%$ silt, $47.5 \%$ sand and $5 \%$ marble powder (NS5\%MP), Group 4 is $45 \%$ silt, $45 \%$ sand and $10 \%$ marble powder (NS10\%MP), Group 5 is $40 \%$ silt, $40 \%$ sand and $20 \%$ marble powder (NS20\%MP).

Table 2. Physical properties of soil groups.

\begin{tabular}{|l|c|c|c|c|c|}
\hline & N & NS & $\begin{array}{c}\text { NS5\% } \\
\text { MP }\end{array}$ & $\begin{array}{c}\text { NS10\% } \\
\text { MP }\end{array}$ & $\begin{array}{c}\text { NS20 } \\
\text { \%MP }\end{array}$ \\
\hline LL (\%) & 65 & 32 & 30 & 29 & 26 \\
\hline PL (\%) & 36 & 20 & 17 & 19 & 15 \\
\hline PI (\%) & 29 & 12 & 13 & 10 & 11 \\
\hline LS (\%) & 18 & 9 & 10 & 10 & 9 \\
\hline $\mathrm{w}_{\text {opt }}(\%)$ & 26 & 17.5 & 15.5 & 15 & 15.3 \\
\hline $\begin{array}{l}\rho_{\text {drymax }} \\
\left(\mathrm{kg} / \mathrm{m}^{3}\right)\end{array}$ & 1380 & 1690 & 1740 & 1790 & 1781 \\
\hline
\end{tabular}

Physical properties including Atterberg limits, linear shrinkage, optimum water content and maximum dry density values from standard Proctor compaction test of all soil groups are presented in Table 2. It can be observed that there is a significant reduction in consistency limits with sand addition which remains almost the same with marble inclusion. Sand and marble powder inclusion increase the maximum dry density while considerably reduce the optimum water content.

\subsection{Volume Change}

\subsubsection{One-dimensional swell}

One-dimensional swell test (ASTM D4546-08) was conducted on all of the soil groups at curing times of 0,7 and 28 days. Primary swell potential of silt was as high as $4.95 \%$. Swell potential decreased to $0.67 \%$ after addition of sand. Studying the swell percentages presented in Figure 1 , it can be observed that addition of $5 \%$ and $10 \%$ 
MP to silt-sand mixture initially increased the swell potential which followed by a considerable reduction with time. $10 \%$ and $20 \%$ MP additions have been very effective, keeping the swell potential below the critical limit of $1.5 \%$ at all curing times.

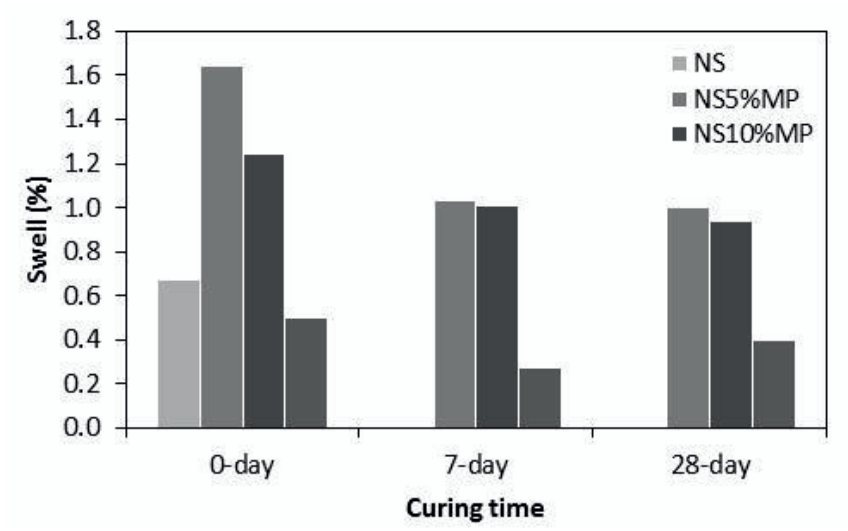

Figure 1. Primary swell percentage change with curing time.

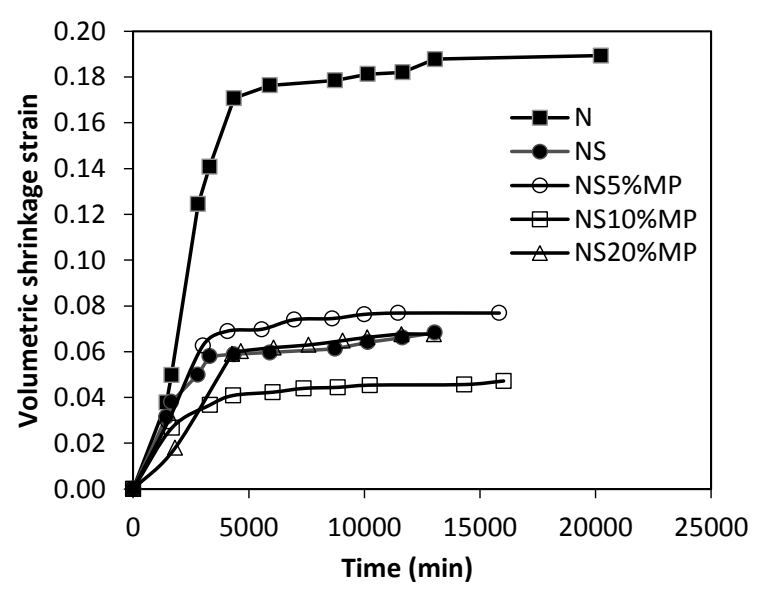

Figure 2. Volumetric shrinkage strain versus time.

\subsubsection{Volumetric shrinkage}

Shrinkage test results were studied as volumetric shrinkage strain $\left(\Delta \mathrm{V} / \mathrm{V}_{0}\right)$ versus time as plotted in Figure 2. Maximum volumetric shrinkage strain of $\mathrm{N}$ was 0.19 which reduced significantly to 0.068 when sand was added. This value reduces furthermore to 0.045 with $10 \%$ MP inclusion after 28 days curing, whereas 5\% and $20 \%$ MP yielded higher volumetric strains. As it can be seen from test results the lowest and most convenient value was obtained after addition of $10 \%$ marble powder. Shrinkage test results were also modelled by SoilVision software [16] using a hyperbolic model given in Equation (1).

$$
e(w)=a_{s h}\left[\frac{w^{c_{s h}}}{b_{s h}{ }^{c_{s h}}}+1\right]^{\left(\frac{1}{c_{s h}}\right)}
$$

where, $a_{\text {sh }}$ : fitting parameter (minimum void ratio), $b_{\mathrm{sh}}$ : fitting parameter (shrinkage limit), $\mathrm{c}_{\mathrm{sh}}$ : fitting parameter (curvature of the hyperbola), w: gravimetric water content.

Table 3 shows the fitting parameters for all soil groups. The results reveal that $10 \% \mathrm{MP}$ gives the best result in shrinkage, as the shrinkage limit (b parameter) and the final void ratio (a parameter) remain the highest after 28 days curing period.

\subsubsection{Prediction of ultimate swelling and shrinkage}

The shape of swell (\%) and volumetric shrinkage strain versus time graphs resemble the shape of a rectangular hyperbola. Kondner (1963) [17] suggested that the nonlinear stress-strain curves of soils represented by a rectangular hyperbolic equation, could be linearized by plotting the results in a modified form. Therefore, swelltime and volumetric shrinkage strain-time relationships could also be linearized [18-20]. Hence using this concept the ultimate swell and volumetric shrinkage strain could be predicted using the hyperbolic model given in Equation (2). Komine and Oggata (1994) [21] proposed to obtain the maximum values by finding the limiting value at infinite time as given in Equation (3).

$$
S(t)=\frac{d h(t)}{h_{o}}=\frac{t}{(a+b t)}
$$

$$
S_{\max }=\lim _{t \rightarrow \infty}\left(\frac{1}{\frac{a}{t}+b}\right)=\frac{1}{b}
$$

where $t$ is the time from the start of water inundation, $S(t)$ is the vertical swell at time $t$, and $a$ and $b$ are constants obtained from straight line fits giving the highest $\mathrm{R}^{2}$ value.

Theoretically, it takes infinite time to reach the ultimate swell value, which cannot be practically measured in the laboratory. Therefore, prediction from the initial stages of swell is advantageous instead of continuing till equilibrium. Addition of sand and MP have yielded both predicted swell and shrinkage percentages slightly bigger than the measured values as

Table 3. Hyperbolic fitting parameters of the shrinkage curves.

\begin{tabular}{|l|c|c|c|c|c|c|c|c|c|}
\hline \multirow{2}{*}{ Material } & \multicolumn{3}{|c|}{ 0-day } & \multicolumn{3}{c|}{ 7-day } & \multicolumn{3}{c|}{28 -day } \\
\cline { 2 - 11 } & $\mathrm{a}$ & $\mathrm{b}$ & $\mathrm{c}$ & $\mathrm{a}$ & $\mathrm{b}$ & $\mathrm{c}$ & $\mathrm{a}$ & $\mathrm{b}$ & $\mathrm{c}$ \\
\hline NS & 0.401 & 0.143 & 9.469 & - & - & - & - & - & - \\
\hline NS5\%MP & 0.410 & 0.164 & 8.522 & 0.480 & 0.190 & 46.81 & 0.472 & 0.174 & 7.38 \\
\hline NS10\%MP & 0.439 & 0.173 & 14.66 & 0.476 & 0.179 & 29.92 & 0.503 & 0.181 & 25.5 \\
\hline NS20\%MP & 0.456 & 0.191 & 6.031 & 0.422 & 0.146 & 16.52 & 0.425 & 0.150 & 6.74 \\
\hline
\end{tabular}


can be observed in Figure 3 (a) and (b).

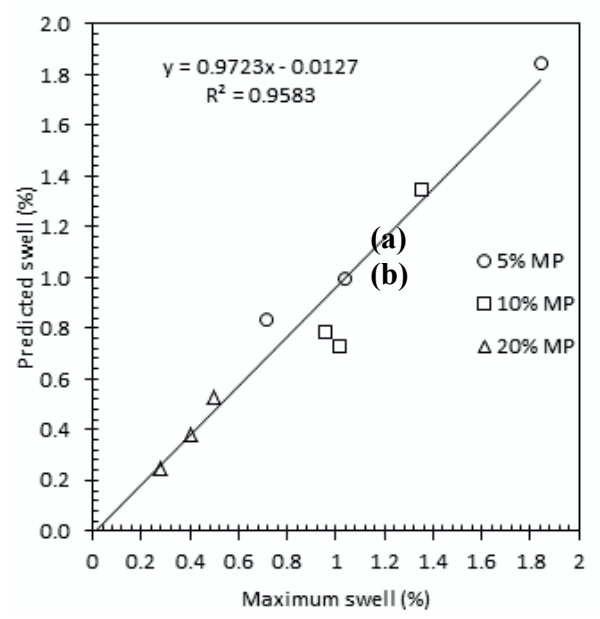

(a)

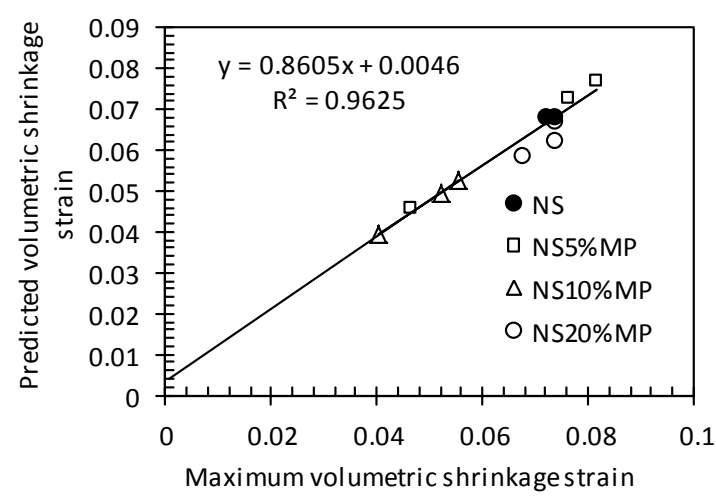

(b)

Figure 3. Predicted swell (a) and volumetric shrinkage strain (b) versus measured maximum swell and shrinkage strains.

\subsection{Flexural Strength}

Flexural strength tests were performed for all soil groups at different curing times, and load-deflection curves were obtained. The peak flexural load $\left(\mathrm{P}_{\mathrm{f}}\right)$ of each mixture at different curing times are obtained and displayed in Table 4. The flexural performance of compacted stabilized soil mixture displays either deflection-softening or deflectionhardening behavior. From the flexural load versus deflection curves, the point at which the linearity of the load-deflection curve ends $\left(\mathrm{P}_{1}\right)$, the initial peak, also known as the limit of proportionality (LOP) as described in ASTM C1609-10 is determined and compared with the peak flexural load $\left(\mathrm{P}_{\mathrm{f}}\right)$. In this study both values are almost equal, therefore, the flexural behavior is deflection-softening, conversely if $\mathrm{P}_{1} \mathrm{P}_{\mathrm{f}}$ is greater than 1 , deflection-hardening occurs. This can further be justified by determining the equivalent flexural strength ratio given in Equation (4).

$$
R_{T, 150}^{D}=\frac{T_{150}^{D}}{P_{1} \frac{L}{150}}
$$

where $R_{T, 150}^{D}$ is the flexural strength ratio, $T_{150}^{D}$ is toughness which is the area under the load-deflection curve from 0 to $\mathrm{L} / 150(0.6 \mathrm{~mm})$ deflection.

Flexural strength values are obtained by using Equation (5).

$$
f=1.5 \frac{P L}{b d^{2}}
$$

where, $\mathrm{P}$ is the flexural load, $\mathrm{L}$ is the span length, $\mathrm{b}$ is the width and $\mathrm{d}$ is the depth of the beam.

Toughness is the ability of a material to absorb energy during fracture $[22,23]$. The equivalent flexural strength ratio represents the efficacy of energy absorption of the material from the beginning to the deflection of $\mathrm{L} / 150$. If this value is less than $100 \%$, deflectionsoftening, and if greater than $100 \%$ deflection-hardening behavior occurs. The latter indicates a high toughness material. Table 4 summarizes the flexural strength performance data from which it can be deduced that the toughness value after 28-day curing period is the highest for NS10\%MP specimen. This is also justified by the flexural strength ratio, $R_{T, 150}^{D}$, which yields the highest value with $10 \% \mathrm{MP}$ usage after the curing period of 28 days. However all samples display a strain-softening behaviour, hence utilization of waste marble powder made soil specimens more brittle.

With an attempt to correlate volumetric and axial $\left(\Delta \mathrm{H} / \mathrm{H}_{0}\right)$ shrinkage strains and the flexural strength parameters, the relationships in Figure 4 were produced. There appears to be a logarithmic relationship between the shrinkage strains and the flexural strength and toughness values. Figure 4 depicts that higher the flexural strength and toughness lower will be the desiccation deformations in a semi-arid climate where unsaturated soils prevail. It can also be noted from these findings that the volumetric shrinkage strains are almost twice the axial shrinkage strains. 
Table 4. Flexural performance data.

\begin{tabular}{|c|c|c|c|c|c|c|c|c|c|c|}
\hline \multirow{3}{*}{$\begin{array}{l}\text { Flexural } \\
\text { properties }\end{array}$} & \multirow{2}{*}{ NS } & \multicolumn{3}{|c|}{ NS5\%MP } & \multicolumn{3}{|c|}{ NS10\%MP } & \multicolumn{3}{|c|}{ NS20\%MP } \\
\hline & & $0-d$ & $7-d$ & $28-d$ & $0-d$ & $7-d$ & $28-d$ & $0-d$ & $7-d$ & $28-d$ \\
\hline & 78.91 & 50.86 & 69.66 & 92.7 & 80.18 & 98.98 & 80.18 & 46.4 & 65.13 & 69.66 \\
\hline $\mathrm{P}_{1}(\mathrm{~N})$ & 35 & 22 & 30 & 40 & 34 & 42 & 34 & 20 & 28 & 30 \\
\hline $\begin{array}{l}\text { Flexural strength } \\
(\mathrm{kPa})\end{array}$ & 78.91 & 50.86 & 69.66 & 92.7 & 80.18 & 98.98 & 80.18 & 46.36 & 65.13 & 69.66 \\
\hline Toughness (Nmm) & 11 & 6.3 & 10.1 & 7.3 & 13.2 & 12 & 9.5 & 7.5 & 6.7 & 6.8 \\
\hline$R_{T, 150}^{D}(\%)$ & 52 & 48 & 56 & 30 & 65 & 48 & 47 & 63 & 40 & 38 \\
\hline
\end{tabular}

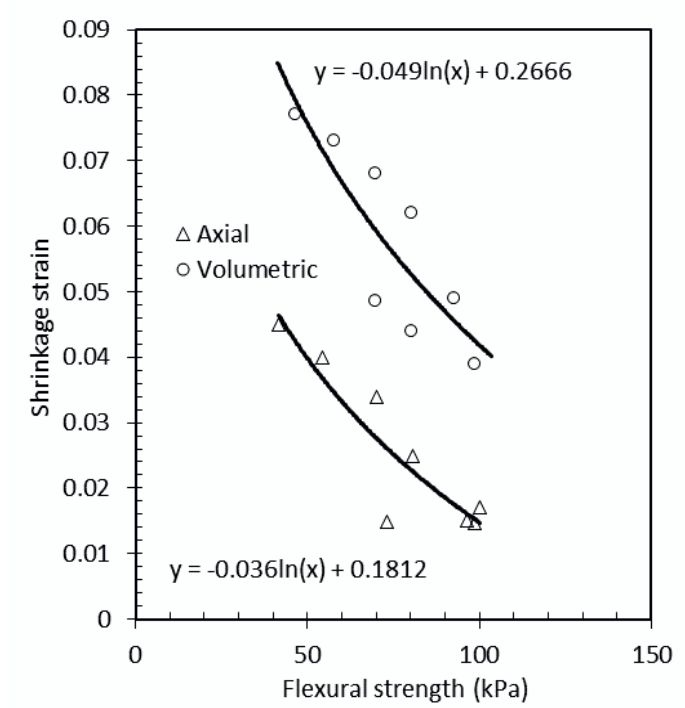

(a)

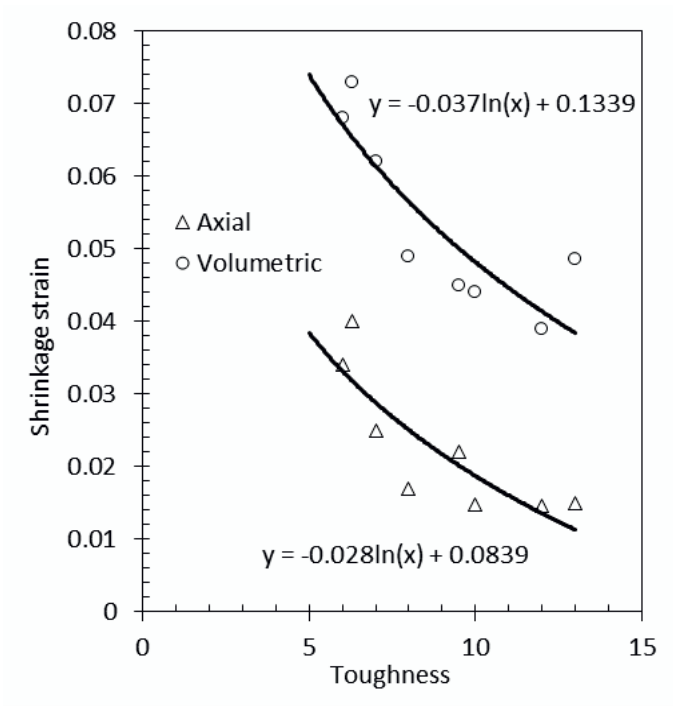

(b)

Figure 4. Relationship between volumetric and axial shrinkage strains and (a) flexural strength and (b) toughness.

\section{Conclusions}

This study summarizes the initial findings of a research which aims to utilize a waste product for recycling purpose, as well as mitigating the expansive soils which cause structural distresses in a semi-arid climate, mainly to light structures. The marble powder produced as a waste product in construction industry has been used to partially replace the sea sand used to mitigate an expansive silt. The research was aimed to study the efficiency of this material in soil stabilization. The experimental findings demonstrated that swell and shrinkage properties improved by at least $10 \%$ MP usage and that the effect of curing has been rather significant. However, regarding the flexural strength properties, it was observed that the MP addition increased the brittleness of the soil mixtures, hence could be recommended for soils to bear light loads. The predictive determinations of maximum swell and shrinkage values were also tested and proved to be very effective. Furthermore, a correlation could be formed between volumetric shrinkage and flexural strength parameters which clearly needs further work to ascertain its applicability to different soils.

\section{References}

1. K. S. S. Rao, S. M. Rao, S. Gangadhara, Swelling Behavior of a Desiccated Clay. Geotechnical Testing Journal 23(2): 193-198 (2000)

2. F. H. Chen, G. S. Ma, Swelling and shrinkage behavior of expansive clays. Proceedings 6th International Conference on Expansive Soils, Vol. 1, New Delhi, India, pp. 127-129 (1987)

3. R. W. Day, Swell-Shrink Behavior of Compacted Clay, Journal of Geotechnical Engineering, ASCE, 120(3), pp. 618-623 (1994)

4. F. H. Chen, Foundations on Expansive Soils, second ed. Elsevier, New York (1988)

5. P. T. Sherwood, State of the art review-Soil Stabilization with Cement and Lime, HMSO publication, London (1993)

6. K.S. Gandhi, Stabilization of expansive soil of Surat region using rice husk ash and marble 
dust. International Journal of Current Engineering and Technology. Vol. 3, No. 4, pp. 1516-1521 (2013)

7. V. Agrawal, M. Gupta, Expansive soil stabilization using marble dust. International Journal of Earth Sciences and Engineering, Vol. 4, No. 6, pp. 59-62 (2011)

8. R. S. Abdulla, N.N. Majeed, Some physical properties treatment of expansive soil using marble waste powder. International Journal of Engineering Research \& Technology. Vol. 3 (1), pp. 591-600 (2014)

9. Ö. Çimen, S. N. Keskin, S. Seven, E. Erişkin, D. Güllü, The effect of waste marble pieces on swelling pressure at compacted clay. Fourth Geotechnical Symposium, (in Turkish), Çukurova University, December 1-2, pp 206211, Adana, Turkey (2011)

10. A. K. Sabat, R. P. Nanda, Effect of marble dust on strength and durability of rice husk ash stabilised expansive soil. International Journal of Civil and Structural Enginering Vol. 1, No. 4, pp. 939-948 (2011)

11. O. Başer, E. Çokça, Stabilization of Expansive Soils Using Waste Marble Dust. 13th National Conference on Soil Mechanics and Foundation Engineering, September 30- October 1, Vol. 1, (in Turkish), pp. 143-152, Istanbul, Turkey (2010)

12. I. Zorluer, M. Usta, Stabilization of Soils by Waste Marble Dust. Fourth National Marble Symposium, December 2003, pp. 305-311 (in Turkish), Afyon, Turkey (2003)

13. T. Cömert, S. Fırat, G. Yımaz, M. Sümer, Reuse of fly ash, marble dust and disposal sand for road subbase fill. 13th National Conference on Soil Mechanics and Foundation Engineering, September 30- October 1, Vol. 1, pp. 153-162 (in Turkish), Istanbul, Turkey (2010)

14. S. Firat, G. Yılmaz, A. T. Cömert, M. Sümer, Utilization of marble dust, fly ash and waste sand (silt-quartz) in road subbase filling materials. KSCE Journal of Civil Engineering. Vol. 16, No. 7, pp. 1143-1151 (2012)

15. C. Gupta, R. K. Sharma, Influence of marble dust, fly ash and beas sand on sub grade characteristics of expansive soil. Journal of Mechanical and Civil Engineering, pp. 13-18 (2014)

16. SoilVision Systems Ltd., SoilVision Theory Guide, Version 3.34, 2nd edition, Saskatoon, Saskatchewan, Canada (2001)

17. R. L. Kondner, Hyperbolic Stress-Strain Response: Cohesive Soils. Journal of Soil Mechanics and Foundations Division, ASCE, Vol. 89, No. SM1. Proc. Paper 3429, pp. 115143 (1963)

18. A. S. Muntohar, Swelling and Compressibility Characteristics of Soil- Bentonite Mixtures, Dimensi Teknik Sipil Vol. 5, No. 2, pp. $93-98$ (2003)
19. H. Nagaraj, M. Munnas, A. Sridharan, Swelling behavior of expansive soils. International Journal of Geotechnical Engineering, Vol. 4, Issue 1, pp. 99-110 (2010)

20. M.A. Dafalla, M.A. Al-Shamrani, Swell and aging effect on a bentonite sand mixture, Unsaturated Soils: Theory and Practice, Kasetsart University, Thailand, ISBN 978-6167522-77-7 1 (2011)

21. H. Komine, N. Ogata, Experimental study on swelling characteristics of compacted bentonite. Canadian Geotechnical Journal, 31 (4), pp. 478490 (1994)

22. S. Onyejekwe, G.S. Ghataora, Effect of fiber inclusions on flexural strength of soils treated with nontraditional additives. Journal of Materials in Civil Engineering, ASCE, 04014039: pp. 1-9 (2014)

23. P. Jamsawang, P. Voottipruex, S. Horpibulsuk, Flexural strength characteristics of compacted cement-polypropylene fiber sand. Journal of Materials in Civil Engineering, ASCE, 04014243: pp. 1-9 (2014) 